\title{
Either sufentanil or fentanyl, in addition to intrathecal bupivacaine, provide satisfactory early labour analgesia
}

\author{
[Le sufentanil ou le fentanyl, ajouté à l'administration intrathécale de bupiva- \\ caïne, fournissent une analgésie satisfaisante au début du travail]
}

Christine Jih-Ching Cheng FRCA, Alex Tiong-Heng Sia MB BS MMED, Evangeline Hua-Ling Lim MB BS, Genevieve Phek-Yee Loke MB BS, Hsiao Ming Tan MB BS MMED

Purpose: The study was aimed primarily at comparing the duration of analgesia produced by intrathecal fentanyl $25 \mu \mathrm{g}$ with sufentanil 5 $\mu \mathrm{g}$ when added to bupivacaine $1.25 \mathrm{mg}$ as the initial component of the combined spinal epidural (CSE) technique in early labour.

Methods: Forty healthy parturients were randomly assigned into two groups to receive either intrathecal sufentanil $5 \mu \mathrm{g}$ plus bupivacaine $1.25 \mathrm{mg}$ (Group S) or intrathecal fentanyl $25 \mu \mathrm{g}$ plus bupivacaine $1.25 \mathrm{mg}$ (Group F). Apart from the duration of analgesia, pain scores and side effects were also evaluated.

Results: There was no significant difference in the duration of analgesia (mean $109 \pm$ SD 49 min in Group F vs $118 \pm 54$ min in Group $S, P=0.9)$. Group $F$ had a more rapid onset of analgesia $(P$ $<0.05$ ) and a higher cephalad block (median T4 vs T7, $P<0.05$ ) in the first 30 min after the block. No difference in the side effects was detected.

Conclusion: Fentanyl $25 \mu \mathrm{g}$ is a good alternative to sufentanil $5 \mu \mathrm{g}$ when added to bupivacaine $1.25 \mathrm{mg}$ for early labour analgesia.

Objectif : Comparer principalement la durée de l'analgésie produite par 25 mg de fentanyl intrathécal ou de 5 mg de sufentanil ajouté à I,25 mg de bupivacaïne comme composant initial d'une analgésie rachidienne et péridurale combinée (RPC) pendant le début du travail.

Méthode : Quarante parturientes en bonne santé ont été réparties au hasard en deux groupes et ont reçu, soit 5 mg de sufentanil intrathécal avec 1,25 mg de bupivacaïne (Groupe S), soit $25 \mathrm{mg}$ de fentanyl avec 1,25 mg de bupivacaïne (Groupe F). On a évalué la durée de l'analgésie en plus de déterminer les scores de douleur et des effets secondaires.
Résultats : La durée de l'analgésie n'a pas présenté de différence intergroupe significative (Groupe $F$ : moyenne de $109 \pm$ écart type de 49 min vs Groupe S: $118 \pm 54 \mathrm{~min}, P=0,9)$. Dans le groupe $F$, le début d'action de l'analgésie a été plus rapide $(P<0,05)$ et le bloc plus élevé en direction céphalique (médiane de T4 vs T7, $P<0,05$ ) pendant les 30 premières min après le bloc. Aucune différence d'effets secondaires n'a été détectée.

Conclusion : L'administration de 25 mg de fentanyl remplace bien celle de $5 \mathrm{mg}$ de sufentanil lorsqu'on l'ajoute à 1,25 mg de bupivacaïne pour l'analgésie du début du travail obstétrical.

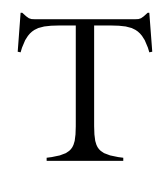

$\mathrm{HE}$ induction of labour analgesia with intrathecal lipid soluble opioids (principally, sufentanil and fentanyl) plus bupivacaine has gained much popularity with the introduction of the combined spinal epidural (CSE) technique. ${ }^{1,2}$ Although bupivacaine $2.5 \mathrm{mg}$ is commonly added to intrathecal fentanyl $25 \mu \mathrm{g}$, there is evidence to suggest that halving the dose of bupivacaine may reduce side effects (such as hypotension and motor block) without unduly compromising the quality of analgesia. ${ }^{3}$ Similarly, we found the combination of sufentanil $5 \mu \mathrm{g}$ plus bupivacaine $1.25 \mathrm{mg}$ to be an effective intrathecal component of CSE for analgesia in early labour as this combination dose produced a lower incidence of side effects than a larger dose of intrathecal sufentanil $10 \mu \mathrm{g}$ plus bupivacaine $2.5 \mathrm{mg}{ }^{4}$

From the Department of Anaesthesia, KK Women \& Children's Hospital, Singapore.

Address correspondence to: Dr. Alex Tiong-Heng Sia, Department of Anaesthesia, KK Women's and Children's Hospital, 100 Bukit

Timah Road, Singapore 229 899. E-mail: athsia@kkh.com.sg

Accepted for publication January 29, 2001. 
The current study was primarily aimed at comparing the duration of analgesia of the commonly used dose of $25 \mu \mathrm{g}$ for fentanyl with sufentanil $5 \mu \mathrm{g}$ when added to intrathecal bupivacaine $1.25 \mathrm{mg}$ for analgesia in early labour. If fentanyl $25 \mu \mathrm{g}$ provides the same duration and quality of analgesia as sufentanil $5 \mu \mathrm{g}$ when added to intrathecal bupivacaine $1.25 \mathrm{mg}$, then the routine use of sufentanil in this regard should be reexamined because of the vast cost difference between the two opioids. In this country, a vial of $\mathbf{5 0}$ $\mu g$ sufentanil costs $\$ 5.00$ US vs $\$ 0.30$ US for a vial of $100 \mu \mathrm{g}$ of fentanyl.

\section{Methods}

With hospital ethics committee approval and written informed consent, 40 nulliparous patients with singleton full-term pregnancies in vertex presentation in early labour (cervical dilatation $2-5 \mathrm{~cm}$, contracting at least once every five minutes) were recruited. The parturients were of ASA status I, without co-existing obstetric or medical complication (such as pre-eclampsia). Parturients who received $i m$ pethidine less than four hours prior to CSE were also excluded. The subjects were randomized by means of sealed envelopes to receive either sufentanil (Janssen Pharmaceutica, Belgium) $5 \mu \mathrm{g}$ (Group S) or fentanyl (David Bull Laboratories, Australia) $25 \mu \mathrm{g}$ (Group F) with bupivacaine $1.25 \mathrm{mg}$. Both mixtures were diluted to a volume of $2.5 \mathrm{ml}$ with normal saline. In each case, the preparation of the injectates was done by an investigator not involved in the administration of CSE and the assessment of the parturients. Only one investigator (C.J.C) was involved in injecting the test solution and the collection of data.

On request for analgesia, the parturients were given $500 \mathrm{ml}$ of compound sodium lactate solution. The procedure was performed at either the $\mathrm{L} 2 / 3$ or $\mathrm{L} 3 / 4$ interspace, with the parturient in the sitting position. The Durasafe ${ }^{\mathrm{TM}}$ combined spinal/epidural anesthesia tray (Becton Dickinson, Franklin Lakes, NJ, USA) was used in all subjects. The epidural space was located with a $17 \mathrm{G}$ Weiss epidural needle via a loss-of-resistance to saline technique. A $27 \mathrm{G}$ high flow variable extension Whitacre needle was then inserted (with its orifice in the cephalad direction) into the subarachnoid space. The free flow of cerebral spinal fluid (CSF) was confirmed by aspirating about $0.1 \mathrm{ml}$ of CSF into the syringe and observing the resultant bisfringens effect. The test solution was then injected over a 30sec period with the help of a stop clock. The spinal needle was then removed and a 19G closed-end multiple-orifice epidural catheter inserted into the epidural space. The catheter was aspirated to exclude intravascular placement before it was secured to the skin. Nothing was administered through this catheter until the first request for analgesia. The parturients were subsequently positioned supine with a $15^{\circ}$ left lateral tilt.

Visual analog pain scores ranging from 0 for no pain to 100 for worst pain imaginable were assessed prior to intervention and at times five, 15 and $30 \mathrm{~min}$ after intrathecal injection. The level of sensory blockade (to ice) and presence of motor blockade was assessed at similar intervals. Motor block was graded as $0=$ no difficulty with straight leg raises; $1=$ unable to flex hip, but able to flex knee; $2=$ unable to flex hip or knee, but able to flex ankle; $3=$ no movement against gravity in all leg joints. The presence of sedation, pruritis, shivering and nausea was also assessed. Sedation was graded as $0=$ none; $1=$ easily arousable by light touch, normal speech; 2 =arousable with loud speech and shaking; $3=$ arousable with painful stimulation; $4=$ unarousable by any means. The other side effects were noted as absent or present. Blood pressure readings were taken prior to intervention and at fiveminute intervals after intrathecal injection for the first $30 \mathrm{~min}$. Hypotension was defined as systolic blood pressure under $90 \mathrm{mmHg}$, and was treated with $5 \mathrm{mg}$ boluses of ephedrine. The variability of cardiotocographic readings was also assessed during this initial 30 -min period. Any changes that required obstetric intervention in terms of drug therapy (terbutaline or nitroglycerine) or emergency Cesarean section was regarded as non-reassuring fetal status. These excluded type I decelerations or variable decelerations that resolved spontaneously after lying the parturient in the full left lateral position. Respiratory depression in terms of respiratory rate slower than eight breaths $\min ^{-1}$ or shallow respiratory efforts was also assessed during this period.

The duration of analgesia was defined as the time interval from intrathecal injection to time of first request for more analgesia. The subjects in whom we failed to obtain clear CSF flow from the spinal needle (after two attempts) were classified as 'technical' failures. They were withdrawn from the study. The envelopes were resealed and reassigned randomly to another parturient. The subjects in whom adequate analgesia was not achieved within 15 min of intrathecal injection were treated as 'analgesic' failures, and 3 $\mathrm{ml}$ boluses of local anesthetic $(0.2 \%$ ropivacaine) injected through the epidural catheter to produce pain relief. Data collected from these subjects in the first 15 min were included in our statistical analysis, and their numbers were not re-assigned. With the exception of duration of analgesia, data from parturients who deliv- 
ered prior to requesting further analgesia were also included.

For statistical analysis, the unpaired Student's t test was used to compare duration of analgesia, the primary aim of our study. Other continuous data (age, height, weight, lowest blood pressure) were also analysed by using the t test. The Mann-Whitney $U$ test was used to assess sensory levels, cervical dilatation and station. Serial pain scores were analysed by the analysis of variance (ANOVA) for repeated measure and posthoc application of Bonferroni's test. Fisher's exact test was used to compare the incidence of hypotension, nausea, shivering, sedation, non-reassuring fetal status, presence of motor block and use of oxytocin.

The sample size was computed to detect a difference in duration of analgesia of $30 \mathrm{~min}$ between the two groups ( $=0.05, \beta=0.2)$ based on the findings of our previous study.

\section{Results}

Of the 40 women enrolled into the study, 20 received sufentanil and 20 received fentanyl as per the protocol. 'Technical' failure was encountered on two occasions. None of the parturients had delivered before request for analgesia was made after the initial intrathecal injection.

There were no demographic differences between the two groups in terms of age, weight, height, cervical dilation or station at the time of intrathecal injection (Table I).

There was no difference in the duration of analgesia between the two groups; the mean duration for Group F was $109 \pm$ SD $49 \min v s 118 \pm 55$ min for Group S, $P=0.9$ (Figure 1) .

There was no significant difference in the baseline pain score between the two groups. One parturient in each group had 'analgesic' failure. Both groups had similar pain scores prior to CSE as well as 15 and 30 min after. At five minutes, the pain score in Group $\mathrm{F}$ was lower, $(P<0.05$ after correction, Table II). The highest dermatomal block to cold was also higher for Group F $(P<0.05$, Figure 2$)$.

No significant differences were found in the two groups with regard to the incidence of pruritis, shivering, sedation, hypotension or fetal distress. There was no clinically demonstrable respiratory compromise (Table III).

\section{Discussion}

The duration of labour analgesia obtained with fentanyl $25 \mu \mathrm{g}$ was similar to that obtained with sufentanil $5 \mu \mathrm{g}$ when these opioids were added to intrathecal bupivacaine $1.25 \mathrm{mg}$. Also, both regimens
TABLE I Maternal demographic data

\begin{tabular}{lll}
\hline & Group $F(n=20)$ & Group $S(n=20)$ \\
\hline Age & $28.8 \pm 4.4$ & $27.9 \pm 5.2$ \\
Weight & $63.4 \pm 6.8$ & $68.1 \pm 11.7$ \\
Height & $156.9 \pm 4.7$ & $157.7 \pm 5.8$ \\
Cervical dilation & $3(1$ to 5$)$ & $3(2$ to 4$)$ \\
Station & $-2(-2$ to 0$)$ & $-2(-2$ to -1$)$ \\
Level & $1: 19$ & $2: 18$ \\
\hline
\end{tabular}

Age (yr), weight $(\mathrm{kg})$ and height $(\mathrm{m})$ are expressed as mean $\pm \mathrm{SD}$, whilst cervical dilatation $(\mathrm{cm})$ and station are expressed as median and range. Intervertebral level of combined spinal epidural insertion is expressed as proportion $\mathrm{L} 2 / 3$ vs $\mathrm{L} 3 / 4$.

No significant differences were found between the two groups.

TABLE II Pain scores

\begin{tabular}{lll}
\hline & Group $F$ & Group $S$ \\
\hline Pain-0 & $80(50$ to 100$)$ & $80(40$ to 100$)$ \\
Pain-5 & $0(0 \text { to } 50)^{*}$ & $10(0 \text { to } 80)^{*}$ \\
Pain-15 & $0(0$ to 55$)$ & $0(0$ to 80$)$ \\
Pain-30 & $0($ all 0$)$ & $0(0$ to 5$)$ \\
\hline
\end{tabular}

Pain scores at baseline, five, 15 and $30 \mathrm{~min}$ after intrathecal injection.

All values are expressed as median and range.

${ }^{*}$ Pain scores were different five minutes after injection. $(P<0.05)$.

TABLE III Side effect profile

\begin{tabular}{lll}
\hline & Group $F$ & Group S \\
\hline Pruritus & $15(75 \%)$ & $17(85 \%)$ \\
Sedation & $6(30 \%) \dagger$ & $4(20 \%) \dagger$ \\
Hypotension & 0 & $1(5 \%)$ \\
Nausea & 0 & 0 \\
Motor block & $1(5 \%)$ & 0 \\
Respiratory depression & 0 & 0 \\
Fetal distress & 0 & 0 \\
\hline
\end{tabular}

Number (percentage) of subjects with pruritus, sedation, hypotension, nausea, motor block, repiratory depression and fetal distress in each group.

No significant differences between the two groups. †All at grade 1 (mild sedation).

produced satisfactory analgesia in $95 \%$ (38 out of 40 ) of the cases studied; as a corollary, both regimens could be recommended under the current circumstances. A further significant dose reduction of either opioid or bupivacaine may not be advisable as this may predispose the parturient to a higher rate of 'analgesic' failure, hence, may not justify the potential risk of breaching the dura in every case. ${ }^{5}$ Furthermore, these doses were not associated with any serious side effects, albeit we recognize our sample size was small. 


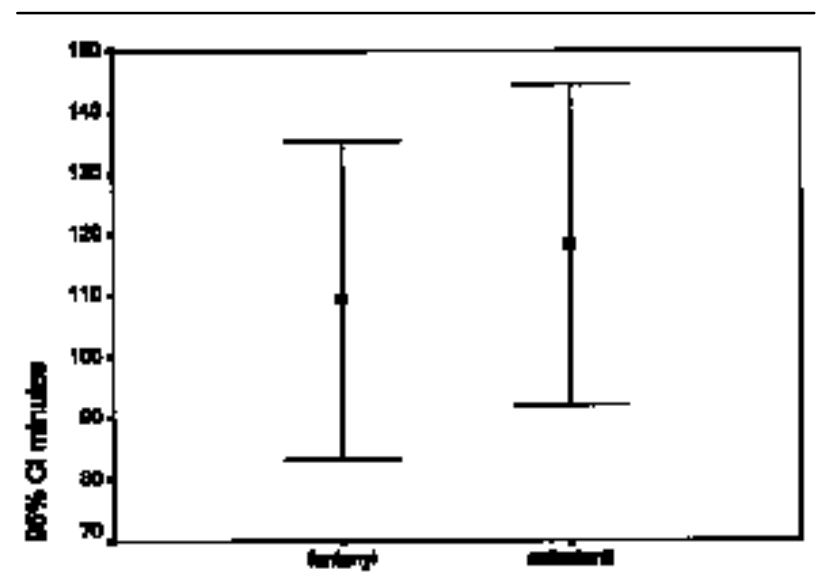

FIGURE I Duration (mean, 95\% confidence interval) of analgesia (min) vs intrathecal opioids. The difference between groups is not statistically significant.

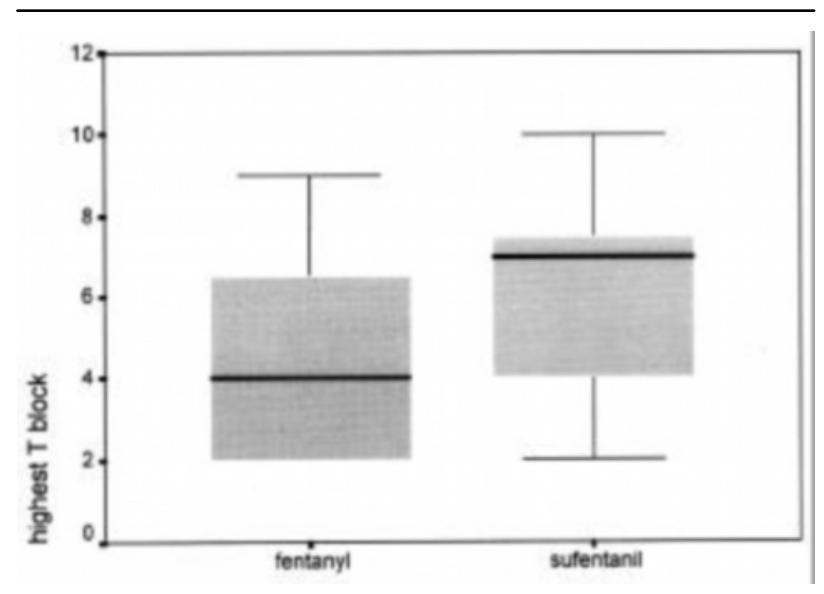

FIGURE 2 Level of highest thoracic block (median, interquartile range, max-min values) $v s$ intrathecal opioids. The difference between groups is statistically significant $(P<0.05)$.

We found the onset of analgesia faster in the fentanyl group compared with sufentanil. This was also associated with a higher level of sensory block during the first $30 \mathrm{~min}$ in the fentanyl group. This could be partially explained by the argument that the fentanyl group was relatively 'overdosed' compared with the sufentanil group. There is indirect evidence to suggest that our dosage ratio of 5:1 (fentanyl: sufentanil) was higher than the potency ratio of 3.2: 1 (f:s) for $\mathrm{ED}_{50}$ values (without the addition of any local anesthetic agent) from two separate studies. ${ }^{6,7}$ However, the validity of extrapolating the potency ratio, as measured by the $\mathrm{ED}_{50}$ for an arbitrary period of analgesia, to the current situation is debatable. Nevertheless, our previous study also showed that doubling the dose of intrathecal sufentanil plus bupivacaine produced a faster and higher cephalad block. ${ }^{4}$

Surprisingly, Palmer et al. noticed a slower onset of block in parturients who had received intrathecal sufentanil compared with fentanyl, in spite of the relatively higher doses of sufentanil injected. ${ }^{6,8} \mathrm{We}$ could not ascertain whether the effect of a lower specific gravity of the fentanyl containing solution (relative to Group S, as inferred from the study by Richardson et al.) played a role in our observation of a faster and higher block in Group F. ${ }^{9}$ The blocks were performed in the sitting position and the density differences of that order have been shown to profoundly affect drug movement in a spinal canal model. ${ }^{9} \mathrm{~A}$ relatively faster rate of drug elimination and block regression in Group $\mathrm{F}$ could account for the lack of clinical difference in terms of the duration of analgesia between the two groups despite the higher block in Group F. By varying baricity, a relatively higher rate of block regression has also been shown with a greater spread of intrathecal bupivacaine although the extension of this relationship to our current protocol needs further evaluation. ${ }^{10}$

Our study shows that both regimens are probably safe for the mother and the fetus, although admittedly, our sample size was small. Only one subject in Group F developed clinically demonstrable unilateral weakness in her hip flexor during the 30- min period. None of the other subjects had any demonstrable motor blockade. The other side effects were either self-limited (pruritus) or clinically insignificant (hypotension).

In conclusion, both sufentanil $5 \mu \mathrm{g}$ and fentanyl 25 $\mu \mathrm{g}$ were effective for analgesia in early labour when administered by intrathecal injection with bupivacaine $1.25 \mathrm{mg}$. Although fentanyl plus bupivacaine produced a faster onset than sufentanil plus bupivacaine, there was no difference in the duration of analgesia between the two groups. The great cost difference between fentanyl and sufentanil behooves that the combination of intrathecal fentanyl $25 \mu \mathrm{g}$ plus bupivacaine $1.25 \mathrm{mg}$ be considered as an alternative to sufentanil $5 \mu \mathrm{g}$ plus bupivacaine $1.25 \mathrm{mg}$ for the induction of analgesia in early labour.

\section{References}

1 Collis RE, Baxandall MI, Srikantharajah ID, Edge G, Kadim MY, Morgan BM. Combined spinal epidural (CSE) analgesia: technique, management, and outcome 
in 300 mothers. International Journal of Obstetric Anesthesia 1994, 3: 75-81.

2 Campbell DC, Camann WR, Datta S. The addition of bupivacaine to intrathecal sufentanil for labor analgesia. Anesth Analg 1995; 81: 305-9.

3 Lee BB, Ngan Kee WD, Hung VYS, Wong ELY.

Combined spinal-epidural analgesia in labour: comparison of two doses of intrathecal bupivacaine with fentanyl. Br J Anaesth 1999; 83: 868-71.

4 Sia ATH, Chong JL, Chiu JW. Combination of intrathecal sufentanil $10 \mu \mathrm{g}$ plus bupivacaine $2.5 \mathrm{mg}$ for labor analgesia: is half the dose enough? Anesth Analg 1999; 88: 362-6.

5 Donglas MJ. Walking epidural analgesia in labour (Editorial). Can J Anaesth 1998; 45: 607-11.

6 Palmer CM, Cork RC, Hays R, Van Maren G, Alves D. The dose-response relation of intrathecal fentanyl for labor analgesia. Anesthesiology 1998; 88: 355-61.

7 Nelson KE, D'Angelo R, Foss ML, Meister GC, Hood $D D$, Eisenach JC. Intrathecal neostigmine and sufentanil for early labour analgesia. Anesthesiology 1999; 91: 1293-8.

8 Herman NL, Calicott R, Van Decar TK, Conlin G, Tilton J. Determination of the dose-response relationship for intrathecal sufentanil in laboring patients. Anesth Analg 1997; 84: 1256-61.

9 Richardson MG, Wissler RN. Densities of dextrose-free intrathecal local anesthetics, opioids, and combinations measured at 37C. Anesth Analg 1997; 84: 95-9.

10 Kooger Infante NE, Van Gessel E, Forster A, Gamulin $Z$. Extent of hyperbaric spinal anesthesia influences the duration of spinal block. Anesthesiology 2000; 92: 1319-23. 